\title{
La transdisciplinariedad una herramienta para transformar la investigación y extensión universitaria
}

\section{Transdisciplinarity a tool to transform university research and extension}

\author{
Alfaro Mardones, Juan Ignacio; Editor Academico Prof. Dr. Carlos A. \\ Zuniga Gonzalez
}

\author{
Juan Ignacio Alfaro Mardones \\ altarrib@ibw.com.ni \\ AREM Matagalpa (UNAN Managua), Nicaragua \\ Editor Academico Prof. Dr. Carlos A. Zuniga \\ Gonzalez \\ Universidad Nacional Autonoma de Nicaragua, Leon, \\ Nicaragua
}

Revista Iberoamericana de Bioeconomía y Cambio

Climático

Universidad Nacional Autónoma de Nicaragua, León, Nicaragua

ISSN-e: 2410-7980

Periodicidad: Semestral

vol. 1, núm. 2, 2015

czuniga@ct.unanleon.edu.ni

Recepción: 11 Septiembre 2015

Aprobación: 15 Octubre 2015

URL: http://portal.amelica.org/ameli/journal/394/3941749008/

DOI: https://doi.org/10.5377/ribcc.v1i2.2477

Autor de correspondencia: altarrib@ibw.com.ni
Resumen: La Universidad Autónoma de Nicaragua (UNAN Managua) desde la Facultad multidisciplinaria de Matagalpa y la Unión de campesinos organizados de San Dionisio (UCOSD) están realizando un diálogo transdisciplinario desde el año 2013. A través de una investigación acción participativa donde se están articulando diferentes niveles de grado y postgrado de la Universidad con las necesidades organizativas, productivas y ambientales de la organización campesina. Desde las carreras de ingeniería agronómica, economía y economía agrícola se ha dialogado con más de 300 familias campesinas organizadas en la subcuenca del río Cálico. En estos diálogos desde las 13 comunidades donde tienen presencia la UCOSD se ha detectado una enfermedad: la organización comunitaria ha muerto dejando paso a una burocracia administrativa que transforma poco a poco de un movimiento social campesino en una empresa prestadora de servicios campesinos. Las contradicciones que sufren los movimientos campesinos y las familias rurales dialogan con las propias contradicciones que sufre la Universidad en su quehacer investigativo y de

extensión. Modelos jerárquicos de poder, visiones del conocimiento encontradas y poco respetuosas, inercias de transferencia y no escucha, dolores personales que cargan mochilas pesadas sobre sus estudiantes o sobre los hijos e hijas de los productores. Estas contradicciones nos ayudan a repensar los modelos de gobierno, los modelos de investigación y extensión y su articulación con docencia que debería impulsar una Universidad para enfrentar los retos y transformaciones de este siglo XXI.

Palabras clave: Transdisciplinariedad, investigación acción participativa, extensión universitaria.

Abstract: The Autonomous University of Nicaragua (UNAN Managua) from the multidisciplinary School of Matagalpa and the Union of peasants organized in San Dionisio (UCOSD) are conducting an interdisciplinary dialogue since 2013. This dialogue is possible through a participatory action research where they are articulating different undergraduate and graduate levels at the University with the organizational, productive and environmental needs of the peasant organization. The different academic degrees of the university such as: agricultural engineering, economics and agricultural economics have had different dialogues with more than 300 peasant families 
organized in the Calico River sub basin. In these dialogues from the 13 communities where the UCOSD is present, a problematic has been detected: community organization has fallen apart giving way to an administrative bureaucracy that gradually transformed a peasant social movement into a company that provides peasants. The contradictions faced by peasant movements and rural families dialogue with the contradictions experienced by the University in its research work and extension. Hierarchical models of power, visions of knowledge are contradicted and little disrespectful, transfer inertia and not listening, personal pains that carry heavy backpacks on their students or the sons and daughters of farmers. These contradictions help us rethink governance models, models of research and extension and its articulation with teaching that should drive a university to meet the challenges and transformations of this century.

Keywords: Transdisciplinarity, participatory action research, university extension.

\section{INTRODUCCIÓN}

La Universidad Nacional Autónoma de Nicarauga, mediante su Facultad Regional Multidisciplinaria de Matagalpa (UNAN-FAREM-Matagalpa) ha establecido alianzas con la Unión de Campesinos Organizados de San Dionisio (UCOSD) a partir de una serie de acciones concretas en diferentes marcos de actuación: tesis de grado y prácticas profesionales desde las carreras de ingeniería agronómica y economía; tesis de maestría en el programa de Maestría en desarrollo rural territorial sustentable; una propuesta de investigación, en el marco del proyecto de la Sociedad Rural, Economía y Recursos Naturales, Integrando competencias en el Desarrollo Rural" (SERIDAR) (Sociedad rural, economia y recursos naturales. Integrando competencias en el desarrollo rural. , 2013) y actualmente tres tesis en el programa de Doctorado en Desarrollo rural territorial sustentable que tratan de articular las prácticas y las tesis de investigación de pregrado de la carrera de economía, agronomía y economía agrícola con este programa de postgrado.

De este vínculo, surgió la demanda de la organización campesina para que les acompañáramos, mediante un proceso participativo y transdisciplinario, "Todo el proceso de investigación surge de demandas que tienen lugar fuera de la academia" (Karlsen \& Larrea, 2015) en el análisis de la realidad socioeconómica y productiva de las familias y comunidades, que permitiera generar un conjunto de propuestas de desarrollo.

Este proceso nos está sirviendo desde la Universidad para repensar el modelo de investigación y extensión que hemos practicado, para hacer una reflexión crítica sobre el mismo y poder identificar y analizar las inercias y las barreras que obstaculizan estos procesos de sacar a la Universidad de las aulas. "es importante diseñar procesos en los que internos y externos dispongan de etapas o fasespara reflexionar por su cuenta antes de reunirse nuevamente para definir el siguiente paso en el proceso de cogeneración de conocimiento relacionado con una nueva definición del problema. De este modo, el proceso continúa de forma ciclica hasta que termina". (Karlsen \& Larrea, 2015)

Notas DE AUTOR 


\section{Materiales y MÉTODOS}

\section{La Investigación acción participativa como marco metodológico para el diálogo transdisciplinario}

"Para iniciar, es preciso recordar que entre 1960 y 1970 se fue gestando en América Latina una corriente amplia de pensamiento en la que confluyeron la Educación Popular, la Teología de la Liberación, la Comunicación Alternativa, la Investigación Acción Participativa y la Filosofía de la Liberación (Torres, 2007). Esta corriente de pensamiento estaba orientada por lo que hoy se conoce como el "paradigma emancipatorio", ya que sus prácticas tenian una clara intencionalidad política, al fortalecer en estos grupos sociales las capacidades que generarian cambios sociales." (Ortiz \& Borjas, 2008)

La Unión de Campesinos Organizados de San Dionisio (UCOSD), es un sujeto colectivo organizado, que ha buscado el desarrollo de sus asociados. A partir de un proceso de reflexión colectiva, iniciado hace aproximadamente hace treinta años, esta organización se ha ido transformando como respuesta a las necesidades internas de sus asociados y a los estímulos externos del contexto sociopolítico y la dinámica tecnoeconómica. He elegido la investigación acción (IA) como mi principal método para la generación de datos. "Como participante, el investigador en la acción tiene el potencial de adquirir una perspectiva holistica del proceso, en lugar de las perspectivas parciales que ofrecen otros métodos. (Karlsen, 2007, p. 59)”. (Karlsen \& Larrea, 2015) La Universidad está desarrollando un dialogo con esta institución y sus participantes, para contrastar sus conocimientos adquiridos en este tiempo, con el saber teórico acumulado por las investigaciones de los docentes involucrados en este programa de investigación.

Al mismo tiempo la IAP nos obliga a posicionarnos como académicos en la elección de los temas, los grupos sociales y los propósitos de nuestras investigaciones. "procesos de investigación en un camino en "espiral" según palabras del educador australiano Stephen Kemmis (1989), quien encontró en esta modalidad de investigación el fundamento de una ciencia social critica bien demarcaa de las corrientes positivistas y bermenéuticas" (Ortiz \& Rojas, 2008; Cabrera, 2002; Garcia duran, 2008)

La investigación se realizará inspirada en la Investigación Acción Participativa, como un método que facilita la transformación social, al mismo tiempo que la generación del conocimiento. "Las competencias de la investigación acción incluyen el aprendizaje de una amplia gama de técnicas de investigación, formas de trabajo, modos de gestionar o facilitar procesos de investigación colaborativos y métodos de documentación y sintesis de los resultados y las implicaciones para la acción. (Greenwood y Levin, 2007, p. 101)"(Karlsen \& Larrea, 2015) Es una investigación con elementos cuantitativos en diálogo permanente con elemento cualitativos y con la aplicación del método teórico, a partir de una reflexión sobre teorías del desarrollo y el empírico, para tratar de hacer dialogar estas propuestas teóricas con la realidad y el saber local, desde un diálogo transdisciplinario, tanto con las personas protagonistas de la UCOSD, así como con el equipo investigador de la UNANManagua. "la tensión entre teoría y práctica que conduce a un diálogo entre saberes teóricos y saberes prácticos convirtiendo al investigador en un educador desde el principio freiriano de la "concientización dialógica". (Ortiz \& Borjas, 2008).

"Existe una diferencia entre un proceso de investigación llevado a cabo exclusivamente por investigadores (en el que el investigador controla el proceso aun cuando interactúa con actores territoriales para obtener datos) y los procesos participativos (en donde el investigador puede influir en un proceso, pero no controlarlo). De hecho, el investigador no tiene derecho a controlar el proceso. La investigación acción es un proceso participativo y los entornos de investigación acción deben crear condiciones favorables para que el investigador influya en el proceso y sea influido por él de manera consciente." (Karlsen \& Larrea, 2015) Y esto implica saber escuchar, sobre todo saber escuchar "La escucha, el reconocimiento del otro, es una modalidad de trabajo que se proclama" y tener la capacidad de cambio abierta. "Ello supone estar dispuestos a replanificar o modificar esquemas y/o cronogramas de trabajo en función de los condicionantes de la organización.” (Avila, Elsegood, Garaño, \& Harguinteguy, 2014)

La necesidad de la transdisciplinariedad en la investigación 
"Vale la pena preguntarse si el cambio climático, la crisis energética, la alimentaria y la financiera, sumados al crecimiento del número de personas pobres, la pérdida de la biodiversidad, entre otros, no constituyen una acelerada march a de los acontecimientos que muestran la obsolescencia del desarrollo. Y cabe preguntarse también en qué medida las Universidades no son un espacio privilegiado para colaborar en la promoción de nuevas ideas, en muchos casos ayudando a revelar la importancia de ciertas prácticas hasta ahora desechadas por el discurso del desarrollo." (Agostino, Junio 2009) En este diálogo, Saúl Úbeda, fundador de la UCOSD y actualmente coordinador contratado por el consejo directivo, nos recuerda desde su experiencia a la academia del peligro de la fragmentación. "Mis mejores momentos eran cuando todos los productores éramos parte de la asociación. La institucionalidad (burocratización) nos dividió y la profesionalización nos fragmentó." (Úbeda, 2014) La multidimensionalidad del desarrollo nos obliga a dialogar con diferentes disciplinas, tanto de las ciencias naturales, como de las ciencias sociales, así que necesitamos conocer los fundamentos epistemológicos y metodológicos de cada una de estas disciplinas para poder usar los criterios de validez y el proceso de investigación válido para cada uno de los aspectos abordados.

El mundo vivido por personas que conviven en las zonas rurales está dotado de significados y profundidades que difícilmente podríamos interpretar sino nos apoyamos en un diálogo transdisciplinario con el resto de los actores. "Llegado a este punto del camino, los aprendizajes son muchos y sabrosos: La necesidad de continuar este diálogo, usar didácticas más sensitivas, no perder la reflexión comunitaria aunque se necesite institucionalizar un movimiento social, el uso de la memoria como método de sanación personal y de diálogo generacional y saber que las alternativas pasan por el camino interior de la ética intersubjetiva y de la conciencia personal." (Alfaro , Fernández, \& González, 2015), Cuadro 1 y 2.

Cuadro 1. Generación de conocimiento tradicional (modo 1) y dialogada (modo2).

CUADRO 1

Generación de conocimiento tradicional modo 1 y dialogada modo2

\begin{tabular}{|c|c|}
\hline Modo 1 & Modo 2 \\
\hline $\begin{array}{l}\text { El conocimiento se crea en el contexto de una } \\
\text { comunidad académica. }\end{array}$ & $\begin{array}{l}\text { El conocimiento se crea en el contexto de su } \\
\text { aplicación. }\end{array}$ \\
\hline $\begin{array}{l}\text { El conocimiento se crea de un modo discipli- } \\
\text { nario. }\end{array}$ & $\begin{array}{l}\text { El conocimiento se crea de un modo transdis- } \\
\text { ciplinario. }\end{array}$ \\
\hline Se necesita conocimiento homogéneo. & Se utiliza conocimiento heterogéneo. \\
\hline $\begin{array}{l}\text { La producción del conocimiento se organiza de } \\
\text { forma jerárquica. }\end{array}$ & $\begin{array}{l}\text { La organización es heterárquica, flexible y tran- } \\
\text { sitoria. }\end{array}$ \\
\hline $\begin{array}{l}\text { El control de calidad se realiza mediante la revi- } \\
\text { sión por pares. }\end{array}$ & $\begin{array}{l}\text { El control de calidad lo llevan a cabo los partici- } \\
\text { pantes en el proceso de creación de conocimiento } \\
\text { mediante la rendición de cuentas. }\end{array}$ \\
\hline
\end{tabular}

Fuente: Adaptado de Karlsen (2007) p. 37, basado en Gibbons et al., (1994). Karlsen \& Larrea, (2015).

Etapas, actividades y participantes del diálogo transdisciplinar

Cuadro2. Participantes diálogo transdisciplinar UCOSD - UNAN por etapas y actividad. 
Revista Iberoamericana de Bioeconomía y Cambio Climático, 2015, vol. 1, núm. 2, Agosto-Diciembre,...

\section{CUADRO2. \\ Participantes diálogo transdisciplinar UCOSD - UNAN por etapas y actividad.}

\begin{tabular}{|c|c|c|c|c|}
\hline $\begin{array}{l}\text { Febrero a } \\
\text { abril } 2014\end{array}$ & $\begin{array}{l}\text { Diagnóstico } \\
\text { transdisciplinar }\end{array}$ & $\begin{array}{l}13 \\
\text { asambleas } \\
\text { comunitarias }\end{array}$ & 240 & 27 \\
\hline $\begin{array}{l}\text { Mayo a } \\
\text { Julio } 2014\end{array}$ & $\begin{array}{l}\text { Diagnóstico } \\
\text { transdisciplinar }\end{array}$ & $\begin{array}{l}\text { Evaluación } \\
\text { diagnóstico }\end{array}$ & 20 & 27 \\
\hline $\begin{array}{l}\text { Agosto } \\
2014\end{array}$ & $\begin{array}{l}\text { Acción } \\
\text { transdisciplinar }\end{array}$ & $\begin{array}{l}\text { Planificación } \\
\text { acción } \\
\text { transdisciplinar }\end{array}$ & 20 & 21 \\
\hline $\begin{array}{l}\text { Septiembre } \\
\text { a } \\
\text { diciembre } \\
2014\end{array}$ & $\begin{array}{l}\text { Acción } \\
\text { transdisciplinar }\end{array}$ & $\begin{array}{l}\text { Mapeo } \\
\text { parcelas } \\
\text { familiares } \\
\text { memoria } \\
\text { comunitaria }\end{array}$ & 220 & 40 \\
\hline $\begin{array}{l}\text { Enero y } \\
\text { febrero } \\
2015\end{array}$ & $\begin{array}{l}\text { Acción } \\
\text { transdisciplinar }\end{array}$ & $\begin{array}{l}\text { Evaluación } \\
\text { resultados } \\
\text { acción }\end{array}$ & 8 & 40 \\
\hline $\begin{array}{l}\text { Marzo y } \\
\text { abril } 2015\end{array}$ & $\begin{array}{l}\text { Acción } \\
\text { transdisciplinar }\end{array}$ & $\begin{array}{l}\text { Planificación } \\
\text { devolución } \\
\text { resultados } \\
\text { acción. }\end{array}$ & 8 & 20 \\
\hline $\begin{array}{l}\text { Abril a } \\
\text { Junio } \\
2015\end{array}$ & $\begin{array}{l}\text { Acción } \\
\text { transdisciplinar }\end{array}$ & $\begin{array}{l}\text { Devolución } \\
\text { resultados }\end{array}$ & 240 & 20 \\
\hline $\begin{array}{l}\text { Abril a } \\
\text { junio } 2015\end{array}$ & $\begin{array}{l}\text { Acción } \\
\text { disciplinar }\end{array}$ & $\begin{array}{l}\text { Historias de } \\
\text { vida } \\
\text { Fundadores } \\
\text { Encuestas } \\
\text { relevo } \\
\text { generacional }\end{array}$ & $\begin{array}{l}20 \\
30\end{array}$ & 20 \\
\hline Julio 2015 & $\begin{array}{l}\text { Acción } \\
\text { transdisciplinar }\end{array}$ & $\begin{array}{l}\text { Evaluación } \\
\text { devolución }\end{array}$ & 8 & 20 \\
\hline Julio 2015 & $\begin{array}{l}\text { Acción } \\
\text { disciplinar }\end{array}$ & $\begin{array}{l}\text { Verificación } \\
\text { parcelas }\end{array}$ & 47 & 20 \\
\hline Julio 2015 & $\begin{array}{l}\text { Evaluación y } \\
\text { cierre } \\
\text { transdisciplinar }\end{array}$ & $\begin{array}{l}\text { Planificación } \\
\text { macro } \\
\text { encuentro } \\
\text { campesino }\end{array}$ & 8 & 5 \\
\hline $\begin{array}{l}\text { Agosto } \\
2015\end{array}$ & $\begin{array}{l}\text { Evaluación y } \\
\text { cierre } \\
\text { transdisciplinar }\end{array}$ & $\begin{array}{l}\text { Invitación } \\
\text { comunitaria } \\
\text { al macro } \\
\text { encuentro } \\
\text { campesino }\end{array}$ & 250 & 3 \\
\hline Septiembre & $\begin{array}{l}\text { Evaluación y } \\
\text { cierre } \\
\text { transdisciplinar } \\
\text { y disciplinar }\end{array}$ & $\begin{array}{l}\text { Macro } \\
\text { encuentro } \\
\text { campesino }\end{array}$ & 150 & 30 \\
\hline $\begin{array}{l}\text { Septiembre } \\
2015\end{array}$ & $\begin{array}{l}\text { Acompañamiento } \\
\text { cierre } \\
\text { transdisciplinar }\end{array}$ & $\begin{array}{l}\text { Entrega } \\
\text { información } \\
\text { financiera } \\
\text { comunitaria }\end{array}$ & 250 & 8 \\
\hline $\begin{array}{l}\text { Octubre } \\
2015\end{array}$ & $\begin{array}{l}\text { Acompañamiento } \\
\text { cierre } \\
\text { transdisciplinar }\end{array}$ & $\begin{array}{l}\text { Sesión } \\
\text { evaluación ciclo } \\
\text { productivo } \\
2015\end{array}$ & 100 & 8 \\
\hline $\begin{array}{l}\text { Noviembre } \\
2015\end{array}$ & $\begin{array}{l}\text { Acompañamiento } \\
\text { cierre } \\
\text { transdisciplinar }\end{array}$ & $\begin{array}{l}\text { Sesión pre } \\
\text { planificación } \\
\text { ciclo } \\
\text { productivo }\end{array}$ & 100 & 8 \\
\hline $\begin{array}{l}\text { Diciembre } \\
2015\end{array}$ & $\begin{array}{l}\text { Acompañamiento } \\
\text { cierre } \\
\text { transdisciplinar }\end{array}$ & $\begin{array}{l}\text { Entrega al } \\
\text { nuevo consejo } \\
\text { directivo y } \\
\text { alianza LP } \\
\text { UCOSD-UNAN }\end{array}$ & 15 & 4 \\
\hline
\end{tabular}


Fuente: Equipo investigador y UCOSD.

Además de estos participantes directos han intervenido como invitados o como acompañantes de los procesos de diálogo:

20 estudiantes de economía agrícola del RUCFA con el Dr. Gustavo Siles en sus prácticas de familiarización.

El equipo capacitador del proyecto SERIDAR: Profesores Gustavo Siles, Mario López y Ana Lisbeth Amaya.

El acompañamiento del grupo del doctorado a una de las sesiones de trabajo en San Cayetano, junto con los dos doctores que facilitaron el módulo de historia agraria. Dr. Bradley y Dr. Guzmán.

El diálogo del grupo de doctorantes con el actual administrador y primer presidente y fundador Saúl Úbeda en el marco del módulo de actores del desarrollo facilitado por el Dr. García-Durán.

El acompañamiento en el terreno de dos asesores del equipo transdisciplinar Dr. Salmerón y Dr. GarcíaDurán.

El acompañamiento de cinco estudiantes de intercambio de la Universidad de Olancho de la carrera de recursos naturales y ambiente en el desarrollo de sus prácticas de campo supervisadas.

\section{Resultados Como APRENDIZAJEs DEL diálogo.}

"El diálogo puede ser el camino para el cambio." (Karlsen \& Larrea, 2015)

Repensando la construcción del conocimiento.

La vía de desarrollo campesina siempre ha sido la base ecológica, si se logra que exista un futuro de la identidad rural, de su lucha por la tierra y el cuido de la misma, si esta vía de desarrollo existe, será más fácil alcanzar el desarrollo. Una idea romántica pero alejada de la práctica vital de los centros urbanos, del contenido mayoritario de las Universidades y de las personas que tienen unos mínimos de comodidad existencial y una huella ecológica mucho más grande que los pueblos indígenas y campesinos que vivieron el buen vivir antes del impulso de la colonización e industrialización occidental. " $Y$ es esta racionalidad instrumental, en tanto reunión de positivismo-liberalismo y sociedad capitalista, lo que ha conducido a la bumanidad por caminos dominados por la explotación de la naturaleza y de los hombres mismos, conformando complejos mecanismos de alienación que, en la mayoria de los casos, se retroalimentan." (Galafassi, 2011) ¿Podría este diálogo transdisciplinar ser una herramienta que apunte a generar en la Universidad un pensamiento crítico que cuestione la sociedad que reproduce?

El diálogo transdisciplinario permite la complementariedad entre las ciencias naturales que se ocupan de los aspectos tangibles del desarrollo rural y los aspectos intangibles e inmateriales presentes y cada vez más importantes para poder hablar de procesos de desarrollo y sobre todo nos permite escuchar a los verdaderos protagonistas de los proceso de desarrollo y escuchar desde su reflexión el conocimiento creado en las comunidades rurales. La Unión de Campesinos Organizados de San Dionisio (UCOSD), es un sujeto colectivo organizado, que ha buscado el desarrollo de sus asociados. A partir de un proceso de reflexión colectiva, iniciado hace aproximadamente hace treinta años, esta organización se ha ido transformando como respuesta a las necesidades internas de sus asociados y a los estímulos externos del contexto sociopolítico y la dinámica tecnoeconómica. La Universidad está desarrollando un dialogo con esta institución y sus participantes, para contrastar sus conocimientos adquiridos en este tiempo, con el saber teórico acumulado por las

investigaciones de los docentes involucrados en este programa de investigación. "La formación de profesionales, desde este enfoque, supera la parcelación y fragmentación al potenciar un proceso a través del cual se funden los saberes necesarios que dinamizan un análisis integral y cientifico de los problemas de la realidad, 
lo que le confiere, a consideración de los autores, su identidad y fundamenta campos de acción necesarios para su desarrollo, que se traducen en los contenidos de disciplinas y asignaturas." (Márquez \& Márquez, 2011)

¿Podrían los diálogos transdisciplinarios ser una herramienta para que las Universidades abandonen las vías fragmentarias de la especialización que tanto daño están haciendo al conocimiento y la sociedad en general?

La cultura institucional, la cultura personal y la transformación institucional.

Una población que vio nacer las estructuras del Estado Nación de Nicaragua y vivía en grandes áreas rurales organizados en torno a estructuras de caciquismo o encomiendas coloniales y donde el pensamiento mágico y la visión mítica forman el centro de gravedad de una población que no ve la posibilidad de acceso a la educación formal de forma mayoritaria hasta el triunfo de la revolución, 160 años después de haber sido formada y moldeada Nicaragua por sus élites gobernantes. "El providencialismo cristiano se combinó con las cosmovisiones religiosas, mágicas y fatalistas, dominantes en las sociedades pre-colombinas, y de esta manera reforzó el pensamiento político y las visiones pre-modernas del orden social, el podery la historia que dominaron la experiencia colonial. Para los indígenas de América, el mundo y la existencia humana estaban regulados, hasta en sus más minimos detalles, por fuerzas sobrenaturales a las que ellos debian obedecer. Después de la independencia de España, el providencialismo se mantuvo como uno de los elementos centrales de la teología católica imperante en América Latina. El pobre desarrollo cultural de la región en general, y del clero católico en particular, facilitaron la reproducción de esta visión hasta el día de hoy."(Pérez-Baltodano, 2008)La secularización nunca tuvo lugar, así que nunca existió la separación iglesia - estado, es decir, valores íntimos de cada persona y formas de desarrollo moral de cada comunidad quedan todavía en su relación de las personas con sus parroquias y pastores; pero las normas sociales y comunitarias están conformadas como un cuerpo de ley

supremo y todas las personas de ese territorio se ven sujetas a su propio orden y normativas. Esta convivencia hace muy difícil la madurez de la institución y un correcto funcionamiento del Estado de derecho. Si en nuestro imaginario existen seres superiores, eppor qué deberían estar sujetos a las restricciones legales del Estado? "La influencia del providencialismo y del pensamiento pragmático-resignado se ha visto interrumpida en más de una oportunidad por movimientos y gobiernos reformistas o revolucionarios que han intentado ampliar los limites de la realidad nicaragüense. Estos movimientos y gobiernos, sin embargo, adoptaron posiciones fundamentalmente voluntaristas, incapaces de reconocer los obstáculos estructurales que condicionan la libertad humana." (Pérez-Baltodano, 2008) Esta asociación nace de las posibilidades del movimiento revolucionario y también de la crítica al paternalismo hacia el campesinado del mismo. Nace de una mística y la confianza asociativa se crea anclada a las coherencias personales de esa mística. Hoy treinta años después la organización languidece, tratando de reconstruir la confianza comunitaria, tratando de encontrar las coherencias personales perdidas, tratando de reencontrarse y de encontrarse en un nuevo contexto conservador.

Una Nicaragua revolucionaria que no ha conseguido romper esta característica en el pensamiento político de las élites. "Durante la campaña para las elecciones del 2006, el otrora revolucionario Frente Sandinista de Liberación Nacional (FSLN), reforzó la cultura religiosa providencialista dominante, y se convirtió en una de las principales expresiones institucionales de la cultura que empuja a nuestras élites a asumir que lo políticamente deseable debe subordinarse siempre a los circunstancialmente posible." (Pérez-Baltodano, 2008)

En la Nicaragua del siglo XXI todavia nos encontramos con una institucionalidad vulnerable Instituciones formales que tratan de asemejarse a los mecanismos que han funcionado en las democracias occidentales, pero que no funcionan por la falta de apropiación y equilibrio con el desarrollo personal de sus principales protagonistas: la sociedad. "El Estado Conquistador funciona dentro de un modelo de autoridad tradicionaly, más concretamente, patrimonial. Los individuos y los gobiernos, que controlan este tipo de Estado, cuentan con un gran poder discrecional para interpretar y aplicar la ley, asi como para distribuir los beneficios de la vida en sociedad."(Pérez-Baltodano, 2008) Una Universidad que hereda en sus estructuras de gobiernos y

en sus procesos electorales parte de esta cultura. Una Universidad que también ha perdido en el caminar la coherencia entre los héroes que recuerda y los comportamientos y actitudes de sus procesos; una Universidad 
bipolar que abraza el discurso religioso del providencialismo sin cuestionamientos desde sus autoridades y en las aulas trata de impulsar las transformaciones sociales. En nuestros diálogos con la organización campesina nos dice a la Universidad que nosotros debemos facilitar que cada comunidad afronte sus propios diálogos, que se definan respecto a que visión quieren empujar y de tendencia quieren responsabilizarse. La Universidad no tiene que decirles que hacer, ya tiene bastante con responsabilizarse de sí misma y tampoco decir lo que la organización quiere oír. Su papel muchas veces será decir lo que nadie quiere oír, ser conciencia crítica del proceso de reflexión. Pero para eso la Universidad y el equipo transdisciplinario debería escuchar su propia conciencia crítica. Si cargamos todo ese pragmatismo resignado en las mochilas, más el duelo por el camino de la responsabilidad, aceptamos la cultura de las autoridades privilegiadas, del servilismo, del arribismo y matamos de raíz la posibilidad de una transformación social auténtica.

Las barreras institucionales y las contradicciones personales.

Hoy la UNAN, al igual que otras muchas organizaciones e instituciones en Nicaragua son herederas de un dolor muy profundo que paralizan los cambios y las transformaciones. "Hemos parido incontables héroes y mártires en la defensa de un territorio que no hemos sabido hacer producir para al menos matar el hambre. Ni siquiera hemos sido capaces de evitar que nuestros ríos se sequen y que nuestros lagos se mueran, junto con nuestras esperanzas. De todas formas, vivimos agarrados de Sandino y de Rubén, pregonando al mundo nuestro cada vez más inexplicable "orgullo de ser nicaragüenses".. (Pérez-Baltodano, 2008) No serán los dolores y las heridas las que no nos permiten reflexionar tranquilos sobre nuestro propio futuro. No será que esa cultura de héroes y mártires que la propia Universidad promueve y que justifica nuestros propios dolores y sobre todo nuestra capacidad para no afrontar esos dolores.

"En esos procesos de lucha a veces sacrificamos el crecimiento personal y los espacios intimos por un ideal más alto, a veces sacrificamos nuestra cercanía a nuestra propia familia, a nuestros hijos e hijas, a nuestro compañero $y$ compañera, pues pensamos que el mundo mejor que construimos les compensará. Y dentro nuestro se concentran dolores, sacrificios, traiciones a nuestra conciencia y a nuestra ética en aras de un desarrollo social futuro. Con el paso del tiempo tratamos de curar estos dolores, de trabajar la salud mental de nuestra conciencia y construir una ética en nuestras relaciones con los y las demás. Muchos grupos de mujeres, jóvenes, ecuménicos, ambientalistas y otras expresiones de los movimientos sociales han brindado y abierto espacios para estos procesos de sanación y desarrollo personal intimo. Y muchas personas se acercaron a estos espacios y empezaron procesos de duelopersonal, de reconstrucción de su afectividad, de reconciliación familiar con los hijos y personas abandonadas por un ideal. Un trabajo que ha comenzado en Nicaragua y en otros muchos paises donde se realizaron luch as y revoluciones sociales. Pero un trabajo lento en sus frutos, a veces un trabajo de generacionespara que los jóvenes puedan entender las actitudes de las generaciones que les antecedieron y para que las personas adultas puedan reconciliarse consigo mismas." (Alfaro, 2009)

La Universidad está compuesta por colectivos y personas que viven con estas contradicciones en sus vidas y experiencias personales “ A pasado demasiado poco tiempo para poder sanar y curar las heridas. Muchas personas siguen con esa separación entre su proceso interno de desarrollo personal y el proceso de representación pública de unos ideales y principios. Pero esos principios e ideales son de todos y todas, construidos por la colectividad y cuando se convierten en realidad es cuando se integran dentro del desarrollo intimos de las personas. Sino encontramos sociedades desfragmentadas y divididas consigo mismas. En Nicaragua se llevan más de treinta años debatiendo sobre la división y polarización sandinismo - antisandinismo; cuando la división más grande y profunda, está dentro de las personas que están en esa dicotomia. Sus experiencias personales, su conciencia y su ética son sacrificadas por una posición pública en la polarización alimentada en todos los espaciospúblicos." (Alfaro, 2009). Trabajadores docentes y administrativos que vivieron las ilusiones, desencantos, pérdidas y duelos de una guerra. Estudiantes que han heredado mochilas

de silencio e historias irresueltas. "Una tarea pendiente y urgente que tenemos que emprender es: la Reconciliación con la historia colectiva, nuestra historia pesa mucho, nos jala hacia atrás y es necesario ponerla en 
su lugar. Reconocer y honrar a los muertos, dejarlos que descansen en paz porque ellos y ellas ya hicieron su tarea para dejar de sobrevivir y empezar a vivir. La transformación social exige energía y entusiasmo." (Cabrera, 2014)

Uno de los momentos más iluminador y esclarecedor del diálogo con esta organización campesina fue cuando hablamos del terreno educativo. Analizaban que en Nicaragua los procesos educativos que se proponían por parte de los movimientos campesinos se vieron truncados por la toma del poder con la revolución sandinista. El ideario de Sandino, la propuesta de Carlos Fonseca eran las transformaciones personales para cambiar Nicaragua. Este proceso interrumpido por el ejercicio del poder, causó mucho daño. "La condición humana nos conduce en tal sentido. Nuestro hacer o no hacer condiciona nuestra forma de existir actual y futura. No somos ni ángeles que pueden transitar sin ni siquiera tocarse con otros cuerpos, ni somos bestias que actúan sólo de acuerdo a lo que sus instintos le indican. Somos humanos es decir seres condenados o agraciados por la condición esencial de seres que pueden cometer y que cometen errores, que pueden asi provocar dolor y sufrimiento en otros y también en si mismos, pero seres que también pueden proveer goce y felicidad a otros y a si mismos." (Elizalde, 2013) Errores y dolores no asumidos por una generación. No transmitidos a la siguiente generación. Una represión del desarrollo humano y sustitución por un desarrollo material. ¿Qué desarrollo cuando hablamos de desarrollo? Hoy esta sustitución de satisfactores por bienes que acompaña a todo proceso de sustitución de ilusiones por cosas, se han materializado más que nunca en la aspiración China del Gran Canal. ¿Cómo afrontará cada integrante de la Universidad estos procesos de sanación personal? Si logro abrir el alma, vivir los duelos de las ilusiones, sueños y conectarme así al resto del mundo. ¿Es la transdisciplinariedad una mirada que me ayuda a este proceso de sanación por el cual pasa toda transformación personal primero y social después?

"El punto de partida de la transformación social somos las personas, comienza con nosotras y nosotros mismos, antes de ver hacia afuera hay que ver hacia adentro, bucear en la profundidad de la historia personal y familiar para identificar miedos, inseguridades, creencias auto limitantes, lealtades, sanar duelos y heridas que cargamos en nuestras mochilas, debido a las profundas lealtades con la cultura del silencio que ha enseñado a negar y ocultar los sentimientos." (Cabrera, 2014) ¿Podría un diálogo transdisciplinar que apunta a las transformaciones personales ser una base para la transformación de las estrategias de extensión e investigación desde la Universidad?

Una organización social como la Universidad, no es la infraestructura, ni son los programas funcionales, sino que es un sujeto social, un sujeto colectivo, una red de personas que cargan las mochilas de Latinoamérica, de su colonización, de sus falsas independencias, de las intervenciones extranjeras, de las guerras de liberación y de las guerras civiles, de años y años de conflictos, del neoliberalismo, de las migraciones no elegidas. Y esas personas para aspirar a realizar transformaciones necesitan sanar, sino buscaran los satisfactores incorrectos, los pseudosatisfactores y la sociedad de consumo se habrá enraizado en sus corazones.

Todo diálogo siempre nos deja más interrogantes que respuestas. ¿Cómo responsabilizarme de un proceso de desarrollo, sino puedo responsabilizarme de mis propias contradicciones? ¿Cómo puede la Universidad obviar sus contradicciones institucionales en un diálogo con las contradicciones campesinas? ¿Cómo dialogar desde mis propias contradicciones con las contradicciones de todas estas personas con las que estamos dialogando? Si las organizaciones tienen los mismos problemas básicos con la Universidad, desconfianzas dentro de la comunidad, desconfianzas dentro de cada departamento, líderes y autoridades con su propia historia irresuelta, maquillaje de los dolores más profundos, vidas simuladas y apuestas por la superficialidad en las relaciones personales y abrazo al consumo como sustituto de la esencia existencial. ¿Cómo podemos apoyarnos con este diálogo? ¿Cómo vincular este diálogo a procesos sinceros de reflexión y sanación? ¿Qué nuevo conocimiento mestizo e híbrido nacerá de estos diálogos?

La transdisciplinariedad como estrategia de transformación de la extensión e investigación universitaria

"¿Qué está haciendo la Universidad para introducir cambios que le otorguen pertinencia a su acción educativa en ambientes complejos?” (Andrade, Méndez, \& Martínez, 2010) La transdisciplinariedad sería una respuesta, 
como diálogo abierto entre la Universidad y los actores sociales es una estrategia para articular la Universidad con procesos de desarrollo endógenos del territorio. Esta experiencia nos permitiría pensar en un modelo de extensión universitaria más acorde a los paradigmas abrazados por nuestra normativa curricular. "Esta concepción dialógica en el abordaje de los procesos de enseñanza que incorpora a otros actores sociales - en este caso, no universitarios - instituye además, otro modelo de construcción ciudadana. Aqui la Universidad abandona el tradicional espacio "iluminador" y se sitúa como un actor más que aporta y también aprende -decididamente aprende - de la realidad." (Avila , Elsegood, Garaño, \& Harguinteguy, 2014)

"Este proceso en territorio incorpora además otros actores no universitarios que en el marco de una perspectiva esencialmente dialógica interactúan, todos enseñan y todos aprenden de los problemas genuinos de la realidad; los sujetos, las organizaciones sociales y, fundamentalmente, la Universidad" (Avila, Elsegood, Garaño, \& Harguinteguy, 2014). A partir de estos tres años de diálogo permanente con más de trescientas familias campesinas, cuatro grupos de pregrado con más de 80 estudiantes, cinco profesores y el equipo de investigador del doctorado se ha generado un conocimiento diferente y contextualizado, a un nivel epistemológico, filosófico y metodológico. Estas evidencias ponen a debate la forma de construcción del conocimiento por nuestra Universidad. " (...) la no neutralidad del saber, la perspectiva dialógica en la construcción del conocimiento, la ponderación de la cotidianeidad como un espacio clave en las disputas de sentido, la desnaturalización de la realidad como trabajo necesario para transformarla y la extensión universitaria como un proceso de enseñanza creativo y transdisciplinar." (Avila , Elsegood, Garaño, \& Harguinteguy, 2014)

Al mismo tiempo la Universidad se cuestiona sus propias contradicciones internas. Al dialogar sobre poder, organización, democracia y otras prácticas cotidianas con otros actores sociales del territorio te permite mirarte hacia dentro. El espejo social nos refleja y no salimos demasiado saludables. "En el plano institucional, las

experiencias en comunidad ponen en debate el modelo ético de ser Universidad, reconsiderando el sentido de sus decisiones, sus acciones y también de sus contradicciones y omisiones."(Avila, Elsegood, Garaño, \& Harguinteguy, 2014) Cómo vamos a pedir estructuras democráticas en una organización campesina, cuando en la Universidad el voto no es universal y los órganos de dirección no son asamblearios. Nuestra práctica jerárquica del poder no nos permite aportar al debate desde una verdadera experiencia y al mismo tiempo encontramos las mismas contradicciones que esta organización en nuestra vida institucional.

"Es, en este sentido, que insistimos en que las preguntas que estos procesos despiertan son mutuas y se dan en forma cruzada: desde el interior de la "comunidad académica" y del territorio del que formamos parte, para interpelar a la Universidad pública y al quehacer de sus tres funciones centrales: enseñanza, investigación y extensión." (Avila , Elsegood, Garaño, \& Harguinteguy, 2014) De estas preguntas mutuas, de este diálogo transdisciplinar podría resultar un desarrollo y una transformación de la Universidad; construir un conocimiento pertinente desde la investigación y la extensión que luego se debata en las aulas (docencia); voltear los vértices del triángulo y que la extensión e investigación se antepongan a la docencia; y así aspirar a ser un actor realmente importante en las transformaciones necesarias y urgentes de este siglo XXI. " $E l$ investigador en la acción debe ser consciente de la necesidad de contribuir a la academia desde la experiencia. Por consiguiente, nuestra interpretación de los tres pilares de la investigación acción propuestos por Greenwoody Levin (2007) es que un investigador en la acción no solo está involucrado en investigación, acción y participación, sino que debe desarrollar estas actividades de manera conectada. Por ejemplo, un investigador puede participar en un proceso de cambio y publicar en revistas cientificas. La pregunta es si el escrito se basa en la experiencia que tenga de la participación y la acción, o si es el escrito de un observador externo." (Karlsen \& Larrea, 2015) Una vez más, ¿cuál es nuestra coherencia interna para llevar a cabo estas transformaciones?

Necesitamos desaprender y abandonar la disciplina tradicional de la academia, probar la indisciplina para ser un poco más integrales en nuestros abordajes. "la integralidad-que tomamos como uno de los conceptos rectores 
de esta propuesta - no puede ser pensada únicamente en términos de articulación de las funciones de docencia, investigación y extensión. Es preciso connotar un trabajo interdisciplinario e indisciplinado en pos de la construcción de conocimiento y de un desarrollo intersectorial en diálogo con las organizaciones sociales" (Avila , Elsegood, Garaño, \& Harguinteguy, 2014)

No podremos trabajar en esas transformaciones, mientras no nos transformemos. "Cuando hay una cantidad de dolor acumulado se pierde la capacidad de comunicarse con los demás. En quienes tienen cantidad de traumas personales sin resolver se disminuye enormemente la capacidad de comunicación, la capacidad de flexibilidad y de tolerancia, se ven afectadas caracteristicas que son vitales para que un ser humano funcione adecuadamente. La falta de solidaridad que hoy lamentamos en Nicaragua tiene que ver con la pérdida de confianza de unos en otros. En este pais se han promovido cantidad de programas de fortalecimiento institucional, (...) pero el fortalecimiento institucional tiene su base en la confianza de unos en otros. $Y$ cuando existe mucho dolor acumulado se pierde la confianza mutua". (Cabrera, 2002) Vivimos y sobrevivimos en un país multiduelos. Y sobre todo se pierde la confianza en uno mismo para impulsar los cambios.

¿Cómo reconstruir el papel de la Universidad en el desarrollo? ¿Cómo reconstruir la confianza entre los actores y adentro de las instituciones? ¿Qué relación tiene la confianza con la coherencia personal? Dialogando con la UCOSD hemos aprendido que la confianza se destruyó cuando el liderazgo empezó a decir cosas diferentes que las que hacía. La pérdida de la coherencia personal destruyó la confianza organizativa. ¿Somos coherentes en la Universidad entre lo que hablamos en el aula y lo que escribimos en nuestros trabajos y hacemos en nuestras vidas personales?

\section{A modo de conclusiones.}

La Universidad se ha asomado al siglo XXI con inercias, estructuras y funcionamientos del siglo XX. La Universidad está siendo testigo de transformaciones económicas, ambientales y sociales que tratamos de investigar y comprender. Las disciplinas cada vez ayudan menos a esa comprensión y el abordaje del conocimiento se está abriendo a una mayor interdisciplinariedad y transdisciplinariedad. Además la Universidad en Nicaragua está anclada en la propia cultura política nacional que frena parte del desarrollo institucional. Finalmente la Universidad está formada por diferentes colectivos humanos: docentes, administrativos y estudiantes que cargan en sus mochilas las historia no resueltas de un territorio descrito por Cortázar como "tan violentamente dulce". En una experiencia de tres años de diálogo transdisciplinar con una organización campesina nos ha servido como espejo para identificar nuestras propias contradicciones institucionales y personales al mismo tiempo que hemos experimentado una forma de construcción del conocimiento dialogada e inclusiva que nos está permitiendo la transformación social en 13 comunidades y más de trescientas familias campesinas. ¿Nos estamos transformando nosotros como investigadores? Por ahora se han articulado asignaturas de prácticas y de investigación de pregrado con procesos de investigación de postgrado promoviendo un modelo de extensión e investigación que permite vislumbrar una Universidad pertinente y adecuada para este siglo XXI.

\section{REFERENCIAS}

Agostino, A. (Junio 2009). Alternativas al desarrollo en América Latina: ¿Qué pueden aportar las Universidades? Revista de ALAI Sede Ecuador, 14-17.

Alfaro, J., Fernández, C., \& González, M. (2015). La transdisciplinariedad una herramienta para apuntar al buen vivir. POLIS, 1-15.

Alfaro, J. I. (2009). En defensa al derecho a existir. Polémica $N^{\circ} 95$ (abril), 15-16.

Andrade, R., Méndez , R., \& Martínez, D. (2010). Desterritorializaciones educativas para la Unviersidad de la sociedad del conocimiento. POLIS, 2-16. 
Avila , R., Elsegood, L., Garaño, I., \& Harguinteguy, F. (2014). Universidad, territorio y transformación social. Avellaneda: Undav Ediciones 2014.

Cabrera, M. (2002). Vivimos y sobrevivimos en un país multiduelos. Envio.

Cabrera, M. (2014). Los desafíos de las metodologías sociales para las transformaciones sociales. Managua: Los aleteos verdes.

Elizalde, A. (2013). Desarrollo a escala humana: una opción para el futuro. Desarrollo a escala humana (pág. 15). Matagalpa: Banco Central de Nicaragua.

Greenwood, D. \& Levin, M. (2007) Introduction to action research (2nd ed.). Thousand Oaks, CA: Sage Publications.

Galafassi, G. (2011). La construcción mancomunada y dialéctica de un nuevo proceso de conocimiento para una nueva sociedad. En I. Farah , \& L. Vasapollo, Vivir bien: ¿Paradigma no capitalista? (págs. 263-278). La Paz (Bolivia): CIDES-UMSA; OXFAN; Sapienza Universita de Roma.

García-Duran, R. (2008). Contra la miseria de la economía, hacia la plenitud de la fraternidad. Barcelona: Ediciones Attac Catalunya.

Karlsen, J. (2007). The Regional Role of the University: A Study of Knowledge Creation in the Agora between Agder University College and Regional Actors in Agder. Tesis en la NTNU. 2007, p. 91. Trondheim: Universidad Noruega de Ciencia y Tecnología.

Kemmis, S. (1989). Improving schools and teaching through educational action research. Singapore journal of education, 26, 6-30.

Karlsen, J., \& Larrea, M. (2015). Desarrollo territorial e investigación acción. Donostia - San Sebastian: Orkestra Instituto Vasco de Competitividad.

Márquez, D., \& Márquez, L. (2011). La formación de profesionales. Hacia una aproximación al buen vivir. En I. Farah, \& L. Vasapollo, Vivir bien: ¿Paradígma no capitalista? (págs. 279-290). La Paz (Bolivia): cides-umsa.

Ortiz, M., \& Borjas, B. (2008). La Investigación Acción Participativa: aporte de Fals Borda a la educación popular. Espacio Abierto, Vol. 17, Núm. 4, 615-627.

Pérez-Baltodano, A. (2008). Entre el Estado Conquistador y el Estado Nación. Managua: Instituto de Historia de Nicaragua y Centroamérica de la UCA.

Sociedad rural, economía y recursos naturales. Integrando competencias en el desarrollo rural. . (2013). Proyecto de actualización de los enfoques y estrategias de desarrollo de la UCOSD. Matagalpa: SERIDAR - UNAN FAREM Matagalpa.

Torrez, A. (2007). La educacion popular. Trayecotira y actualidad. Ediotirial El Buho Bogota. Colombia.

Úbeda, S. (11 de marzo de 2014). La UCOSD como actor social. (M. d. sustentable, Entrevistador) 